\title{
Research and Application of Fuling Shale Gas Anti-Collapse and Anti-Leakage Drilling Fluid System
}

\author{
Baijing Wang, Chunzhi Luo, Yidi Wang \\ College of Chemistry and Environmental Engineering, Yangtze University, Jingzhou, China \\ Email:2361599192@qq.com
}

How to cite this paper: Wang, B.J., Luo, C.Z. and Wang, Y.D. (2021) Research and Application of Fuling Shale Gas Anti-Collapse and Anti-Leakage Drilling Fluid System. Open Journal of Yangtze Gas and Oil, 6, 60-71.

https://doi.org/10.4236/ojogas.2021.62006

Received: March 29, 2021

Accepted: April 27, 2021

Published: April 30, 2021

Copyright $\odot 2021$ by author(s) and Scientific Research Publishing Inc.

This work is licensed under the Creative Commons Attribution-NonCommercial International License (CC BY-NC 4.0).

http://creativecommons.org/licenses/by-nc/4.0/

\begin{abstract}
Aiming at the problems of microfracture development in hard brittle shale gas layer in Fuling block, Chongqing, such as collapse of borehole wall and the existence of permeability loss of microfracture during drilling, and serious pollution of drilling environment with oil-based drilling fluid, a water-based drilling fluid system for anti-collapse and anti-leakage was studied. A water-based drilling fluid system with anti-collapse and anti-leakage was formed by introducing functional treatment agents, such as polypolysaccharide MEG, polymer emulsion film forming wall cementing agent LFGB, polyamine inhibitor LCFA and deformable particle plugging agent BXLZ, into the conventional water-based drilling fluid. After rolling at $130^{\circ} \mathrm{C}$ for $16 \mathrm{~h}$, the system has good rheological properties, low filtration loss, good inhibition, lubrication and plugging properties. It has good plugging properties for $0.12 \mathrm{~mm}$, $0.24 \mathrm{~mm}, 0.38 \mathrm{~mm}$ micro-cracks and $400 \mathrm{mD}$ and $800 \mathrm{mD}$ sand plates. The system was successfully tested on site in August 2019 in Fuling Reef Block, showing good rheological properties, solid wall plugging, and strong ability to seal and inhibit fracture expansion. There was no block falling in the drilling process, and the tripping, casing running and well cementing operations were all smooth, which provided a new technical idea and scheme for environmental protection and green drilling in Fuling shale gas exploitation.
\end{abstract}

\section{Keywords}

Shale, Drilling Fluid, Inhibition, Fluid Loss, Lubricity, Plugging

\section{Introduction}

The hard brittle mud shale reservoir not only has a high content of clay minerals, which is easy to hydrate, expand and disperse, but also is compacted into a 
"page shape", which is easy to flake off and collapse, leading to drilling accidents such as stuck drill or even buried drill string. The "page-like" shale has good permeability, resulting in serious permeability loss during drilling and serious pollution to the environment. Oil-based drilling fluids have good performance, but the cost is relatively high, and subsequent treatment is difficult, and hence application is limited. At present, foreign companies have developed high-performance water-based drilling fluids for shale gas development and achieved good results. However, domestic research and application are still in the preliminary stage [1]-[6], and problems such as hydration expansion, dispersion, peeling and permeability loss have not been well solved, and the horizontal displacement of the completed drilling is generally less than $1300 \mathrm{~m}$.

In order to solve the problems of hydration expansion, dispersion, spalling collapse and permeability loss of shale, two key problems should be solved: the film-forming sealing property of drilling fluid on the surface of borehole wall is strong, the filtration loss is low, the pressure transfer is reduced, and the stability of borehole wall is improved. In addition, even a small amount of filtrate enters the wellbore and does not cause shale hydration and expansion, that is, there is a treatment agent in the drilling fluid to improve the cohesion between the clay lattice. The author introduced the small molecule polyamine inhibitor LCFA into the conventional water-based drilling fluid system, which acted together with $\mathrm{KCl}$ in the conventional system to improve the cohesion of clay lattice and prevent the hydration and expansion of mud shale. Polysaccharide MEG and polymer emulsion film forming wall cementing agent LFGB were introduced to improve the lubricating property of drilling fluid. The polymer emulsion film forming and wall cementing agent LFGB can also cooperate with other polymers in drilling fluid to adsorb on the surface of borehole wall to form a waterproof film, which can reduce the penetration of drilling fluid filtrate to shale fractures, reduce pressure transfer and improve the stability of borehole wall. The deformed particle plugging agent BXLZ was introduced to seal the permeable fractures, further reducing the pressure transfer and reducing the sticking accident of mud shale spalling block during drilling. To solve the problems of shale hydration expansion, dispersion, spalling collapse and permeability loss, serious environmental pollution of oil-based drilling fluid drilling, etc, research on water-based drilling fluid system for preventing collapse and leakage has been carried out.

\section{Physical Properties of Shale in Fuling Block}

The shale reservoir of Fuling block in Chongqing is Longmaxi Formation, in which the volume fraction of soluble components such as calcite and feldspar is low and the dissolution pores are well developed. The residual primary intergranular pores in the layers with high volume fraction of rigid minerals such as calcite and quartz are relatively well developed. In the organic matter enrichment section, "honeycomb" organic pores can be seen. The NMR technique was used to determine that the diameter of organic pores in Longmaxi Formation 
shale is concentrated in the range of $2-50 \mathrm{~nm}$, the peak value is $10 \mathrm{~nm}$, and a few organic pores are distributed in the range of $200-500 \mathrm{~nm}$. Inorganic pore diameter has a wide distribution range, ranging from $2.5 \mathrm{~nm}$ to $500 \mathrm{~nm}$, with a peak value of $50 \mathrm{~nm}$ [7] [8].

Shale formation micro cracks in clay minerals enrichment and transformation of clay minerals content seam is relatively developed, the main development in clay minerals and clay minerals and mineral particles between the contact area, micro crack width is small, be in commonly 2 - $3 \mathrm{mu}$, length range is larger, in more than a dozen to hundreds of micrometers, local can reach about $500 \mathrm{mi}$ crons, the main development direction of distribution along the shale formations. Shrinkage of organic matter into rock fractures is generally irregular and serrated. Fracture surfaces of organic matter are irregular and have obvious bifurcation and "wedge" characteristics [9] [10].

The mineral composition of Longmaxi Formation shale in Fuling area is analyzed by $\mathrm{X}$ diffraction method. The results show that it is mainly composed of clay minerals, quartz and carbonate minerals. The clay minerals in the reservoir are mainly characterized by more chlorite and illite and less kaolinite. The integral number of clay mineral objects in shale varies greatly from $14.9 \%$ to $57.1 \%$, with an average of $37.3 \%$. The mass fraction of illite is $21.0 \%-78.0 \%$, with an average of $50.8 \%$, the volume fraction of illite/Mongolian mixed bed is $19.6 \%$, and the volume fraction of chlorite is $10.0 \%-58.0 \%$, with an average of $26.8 \%$. The main volume fraction of brittle minerals, such as quartz and feldspar, ranges from $40.0 \%$ to $82.0 \%$, with a maximum of $90.0 \%$ and an average of $59.6 \%$ [11] [12]. These minerals are typical hard brittle shale.

Based on the analysis of porosity, micro-fracture and shale mineral composition of Longmaxi Formation in Fuling shale segment, it is found that this block belongs to typical hard and brittle shale strata, with low porosity and micro-fracture development, which are the main reasons for instability of wellbore wall, spalling and collapse of shale, sticking of drill and burying of drilling tools during drilling. Therefore, the drilling fluid should not only meet the requirements of sand carrying and suspended sand, but also have very low filtration loss, good lubricity, strong inhibition and plugging.

\section{Research on the Formulation of Drilling Fluid System}

Based on shale gas shale content analysis in Fuling area, choose to prevent mud shale dispersing KPAM package is agent with good effect, salt resistance, temperature of LV PAC, SMP II and SPNH as compound fluid loss agent and can increase the cohesion of clay mineral LFCA polyamine inhibitors and KCL treatment agent, such as mixed density of $1.6 \mathrm{~g} / \mathrm{cm}^{3}$ conventional water-base drilling fluid system, evaluate its basic performance, optimized drilling fluid formula on the basis of four formula. Then, functional treatment agents such as polypolysaccharide MEG, polymer film forming wall cementing agent LFGB and plugging agent BXLZ were introduced into these four formulations to prepare several drilling fluid systems. 
Polysaccharide MEG is a product modified by xanthan gum caramel, which has good lubricity and inhibition. LFGB is a polymer emulsion polymer, which can well adsorb on the cuttings and the surface of the well wall to form an oil film, that is, it can cooperate with other treatment agents to prevent the drilling fluid filtrate from penetrating into the formation, and can prevent the shale from spalling and collapse and the drilling cuttings from dispersing, and has a certain lubricity. Polyamine inhibitor LCFA is a kind of small molecule cation, which has good adsorption and compression double electric layer effect, inhibits drilling cuttings hydration and expansion, improves the cohesion of clay particles, and reduces its expansibility. BXLZ is a kind of solid plugging agent composed of rigid resin and water-absorbing deformation resin with different particle sizes, which can adaptively plug micro-cracks and micro-pores of different sizes. The purpose of introducing these treatment agents is to further improve the inhibition, plugging and lubricity of conventional drilling fluid systems.

A series of drilling fluids prepared were rolled at $130^{\circ} \mathrm{C}$ for $16 \mathrm{~h}$ to determine their rheological properties, API filtration loss, high-pressure and high temperature filtration loss, field shale rolling recovery rate, lubrication and other properties to optimize the best conventional drilling fluid system and anti-collapse and anti-leakage drilling fluid formula:

Conventional drilling fluid system: $3.5 \%+0.2 \% \mathrm{NaOH}+0.15 \%$ sodium bentonite $\mathrm{KPAM}+1 \% \mathrm{LV}-\mathrm{PAC}+3 \%$ SMP SPNH II $+3 \%+5 \%+0.2 \% \mathrm{KCl} \mathrm{XY}-27$ $+3 \%$ XCS $\amalg+$ barite $\left(1.6 \mathrm{~g} / \mathrm{cm}^{3}\right)$.

Collapse of leakage prevention drilling fluid system: $3.5 \%+0.2 \% \mathrm{NaOH}+$ $0.15 \%$ sodium bentonite KPAM $+1 \%$ LV-PAC $+3 \%$ SMP SPNH II $+3 \%+5 \%+$ $0.2 \% \mathrm{KCl} \mathrm{XY}-27+3 \%$ XCS $\amalg+5 \%$ MEG LFGB + 2\% + 0.5\% + 2\% BXLZ LCFA + barite $\left(1.6 \mathrm{~g} / \mathrm{cm}^{3}\right)$.

\section{Performance Evaluation of Drilling Fluid System}

\subsection{Temperature Resistance}

Five cups of $400 \mathrm{ml}$ drilling fluid with a density of $1.6 \mathrm{~g} / \mathrm{cm}^{3}$ were prepared and heated at different temperatures for $16 \mathrm{~h}$, then cooled to $70^{\circ} \mathrm{C}$ and stirred high for $10 \mathrm{~min}$. The rheological properties, fluid loss and viscosity of the drilling fluid at $60^{\circ} \mathrm{C}$ were measured. The experimental results are shown in Table 1.

Table 1. The influence of hot rolling temperature on drilling fluid performance.

\begin{tabular}{ccccccccc}
\hline temperature $/{ }^{\circ} \mathrm{C}$ & \multicolumn{1}{c}{$\mathrm{AV} / \mathrm{mPa} \cdot \mathrm{s}$} & $\mathrm{PV} / \mathrm{mPa} \cdot \mathrm{s} / \mathrm{Pa}$ & $\begin{array}{c}\mathrm{GEL} \\
\mathrm{Pa} / \mathrm{Pa}\end{array}$ & $\mathrm{YP} / \mathrm{PV} / 10^{3} \mathrm{~s}^{-1}$ & $\mathrm{FL}_{\mathrm{API}} / \mathrm{ml} \mathrm{FL}_{\mathrm{HTH}} / \mathrm{ml}^{2}$ & $\mathrm{~K}_{\mathrm{f}}$ \\
\hline 100 & 54.0 & 38.0 & 16.0 & $5 / 7$ & 0.421 & 0.8 & 5.1 & 0.0787 \\
120 & 52.0 & 38.0 & 14.0 & $5 / 7$ & 0.368 & 0.9 & 5.2 & 0.0787 \\
130 & 52.0 & 38.0 & 14.0 & $5 / 7$ & 0.368 & 0.9 & 5.2 & 0.0787 \\
140 & 47.0 & 35.0 & 12.0 & $4 / 5$ & 0.343 & 1.1 & 6.1 & 0.0857 \\
150 & 38.0 & 30.0 & 8.0 & $3 / 4$ & 0.267 & 2.9 & 11.9 & 0.0857 \\
\hline
\end{tabular}

Note: AV: apparent viscosity; PV: plastic viscosity; YP: dynamic shear force; GEL: initial cut/final cut; YP/PV: dynamic plastic ratio. $\mathrm{FL}_{\mathrm{API}}$ : API Filtration Loss; $\mathrm{FL}_{\mathrm{HTHP}}$ : High Temperature and High Pressure Filtration Loss; $\mathrm{K}_{\mathrm{f}}$ : Mud Cake Viscosity Coefficient. Same below. 
The experimental results show that when the temperature is lower than $130^{\circ} \mathrm{C}$, the viscosity and shear force of drilling fluid change little, and the filtration loss and viscosity coefficient remain basically unchanged. At $140^{\circ} \mathrm{C}$, the viscosity and shear force decrease, the filtration loss increases slightly, and the viscosity coefficient also increases slightly, but the overall performance still meets the drilling requirements. At $150^{\circ} \mathrm{C}$, the decrease range of viscosity and shear force increases, the filtration loss increases, the quality of mud cake decreases, and the lubricity is also slightly worse, indicating that the temperature resistance of drilling fluid system is $140^{\circ} \mathrm{C}$.

\subsection{Inhibition}

The main phenomenon of the hard and brittle mud shale soaked in water is the dispersion of the mud shale along the bedding surface. The longer the soaking time is, the finer the dispersion of the mud shale is, accompanied by a certain expansion. In field drilling, the main phenomenon is that the cuttings circulating with the drilling fluid are small, and the shale spalling and falling off the borehole wall is large and angular. Cuttings rolling recovery method can be used to simulate the suppression and dispersion of drilling fluid on cuttings. The volumetric anti-swelling ratio method can be used to simulate the anti-swelling property of drilling fluid system to shale.

1) Rolling recovery rate method

$300 \mathrm{ml}$ of deionized water or drilling fluid to be evaluated was added into the aging tank, and $30 \mathrm{~g} 6-10$ mesh field cuttings were added. After rolling at $130^{\circ} \mathrm{C}$ for $12 \mathrm{~h}$, the cuttings were taken out and cooled to room temperature. The undispersed cuttings were screened by 40 -mesh sample screening and collected in a culture dish. Dry at $105^{\circ} \mathrm{C} \pm 2{ }^{\circ} \mathrm{C}$, weigh the mass of recovered cuttings. The rolling recovery rates of cuttings in deionized water, conventional water-based drilling fluids, anti-caving and anti-leakage drilling fluids and oil-based drilling fluids were evaluated in the laboratory. The experimental results are shown in Figure 1. $c=W / 30 * 100 \%$ ( $c=$ Rolling recovery rate; $W=$ Quality of recovered cuttings).

As can be seen from Figure 1, the rolling recovery rate of cuttings in deionized water is $73.1 \%$, that of conventional water-based drilling fluid is $88.47 \%$,

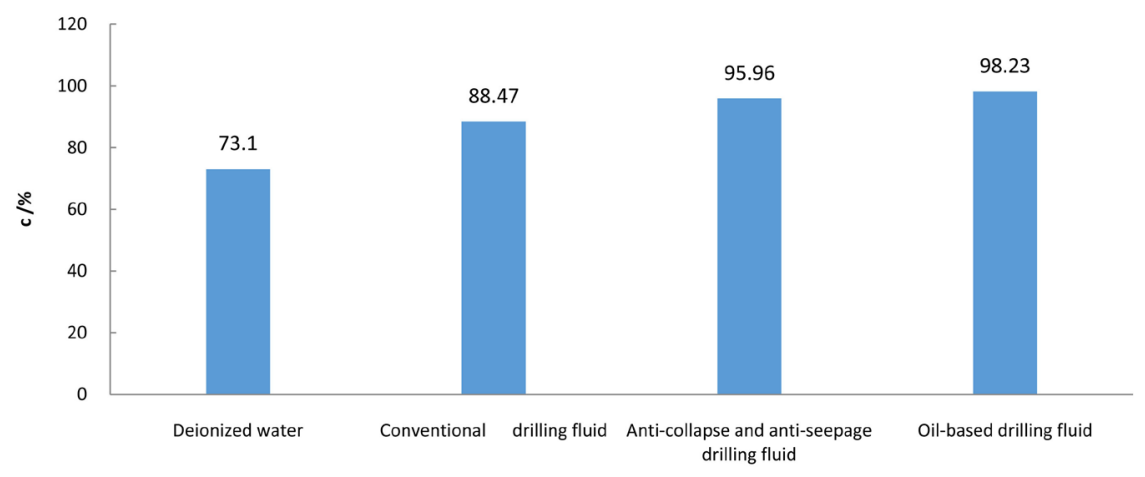

Figure 1. Rolling recovery rate of on-site cuttings in different systems. 
that of anti-collapse and anti-leakage drilling fluid is $95.96 \%$, and that of oil-based drilling fluid is $98.23 \%$. The results show that the hydration and expansion of mud shale are not strong. It does not hydrate into molten form, but disperses into fine particles, and the recovery rate is still $73.1 \%$. The recovery rate of the anti-collapse and anti-leakage drilling fluid is $7.49 \%$ higher than that of the conventional water-based drilling fluid, which is close to the oil-based drilling fluid system, and has strong ability to inhibit the hydration and dispersion of mud shale.

2) Volume anti-expansion rate method

Take the scene cutting grinding particle size is 100 - 200 mesh powder, called $0.5 \mathrm{~g}$ in $10 \mathrm{ml}$ centrifuge tube, add $10 \mathrm{ml}$ deionized water, with fine wire and make it fully dispersed, let stand for $8 \mathrm{~h}$, under the $1500 \mathrm{r} / \mathrm{min}$ speed centrifugal $15 \mathrm{~min}$, read the cuttings powder after expansion volume $V_{1}$, similarly measured cuttings volume where $V_{0}$ powder after expansion in kerosene, after expansion in drilling fluid filtrate volume $V_{2}$. According to the following formula, the volume expansion prevention rate $P$ of drilling fluid filtrate is calculated. The higher the anti-swelling ratio is, the better the anti-swelling ability of drilling fluid filtrate to cuttings is. Volume anti-expansion rate $P=\left(V_{1}-V_{2}\right) /\left(V_{1}-V_{0}\right)$ * 100. The experimental results are shown in Table 2.

As can be seen from Table 2, the volume anti-swelling rate of conventional water-based drilling fluid filtrate is $14.3 \%$ higher than that of anti-collapse and anti-leakage drilling fluid, indicating that the anti-collapse and anti-leakage drilling fluid system has a stronger ability to prevent hydration and expansion of mud shale. In addition, the drilling fluid loss is very small, even if the filtrate into the formation will not cause significant formation hydration expansion, the impact on the pressure balance of the rock around the wellbore is very small, that is, on the stability of the wellbore.

3) Blocking

The maximum pore size of Longmaxi Formation shale in Fuling area is 500 $\mathrm{nm}$, and the microfracture is $0.5 \mathrm{~mm}$. In the process of drilling, the key is to plug such pores and fractures well and reduce the transfer of pressure, so as to effectively reduce the spalling and collapse of mud shale and keep the wellbore wall stable. Particle size analysis was carried out on the anti-collapse and anti-leakage drilling fluids and the conventional drilling fluids, and the plugging ability of the drilling fluids was evaluated by permeability plugging test and pressure transfer test.

a) Article size analysis

LA-950V2 laser particle size analyzer was used to measure the particle size

Table 2. Volumetric anti-expansion rate of on-site cuttings powder.

\begin{tabular}{cc}
\hline Drilling fluid filtrate & Anti-expansion rate \\
\hline Conventional drilling fluid filtrate & $71.4 \%$ \\
Anti-collapse and anti-leakage drilling fluid filtrate & $85.7 \%$ \\
\hline
\end{tabular}


distribution in the sample, and the measured particle size range was $0.01-3000$ $\mu \mathrm{m}$. Prepare for measurement according to the operating procedure of the instrument. Finally, the sample to be tested is placed in the sample tank, and after the sample is fully mixed with the circulating liquid under the action of ultrasonic wave and magnetic stirrer, it flows through the measurement system after circulating through the pump. The measured telecommunication number is fed back to the control system, and the particle size distribution is calculated by the microcomputer. The measurement results are shown in Figure 3 and Figure 4.

According to Figure 2 and Figure 3, the plugging agent particle size of the anti-collapse and anti-leakage drilling fluid is mostly distributed between 100 $500 \mu \mathrm{m}$, while the plugging agent particle size of the conventional drilling fluid is mostly distributed between $10-40 \mu \mathrm{m}$. The maximum microfracture size of the mud shale of Longmaxi Formation in Fuling block is up to $500 \mu \mathrm{m}$. According to the analysis of $2 / 3$ bridge theory, the anti-collapse and anti-leakage drilling fluid should have better plugging ability to the micro-cracks of mud shale in this block.

b) Permeability plugging experiment

Artificial sand discs with permeability of $100 \mathrm{mD}, 200 \mathrm{mD}, 400 \mathrm{mD}$ and 800 $\mathrm{mD}$ were selected to measure the fluid loss (PFL) of high temperature and high pressure sand discs at different time in the conventional water-based drilling fluid system and the anti-collapse and anti-leakage drilling fluid system according to the GB/29170-2012 experimental method by using a permeable plug tester (PPT). The experimental conditions were as follows: temperature $130^{\circ} \mathrm{C}$; Pressure: $3.5 \mathrm{MPa}$.

As can be seen from Figure 4, the filtration loss of sand plates with permeability

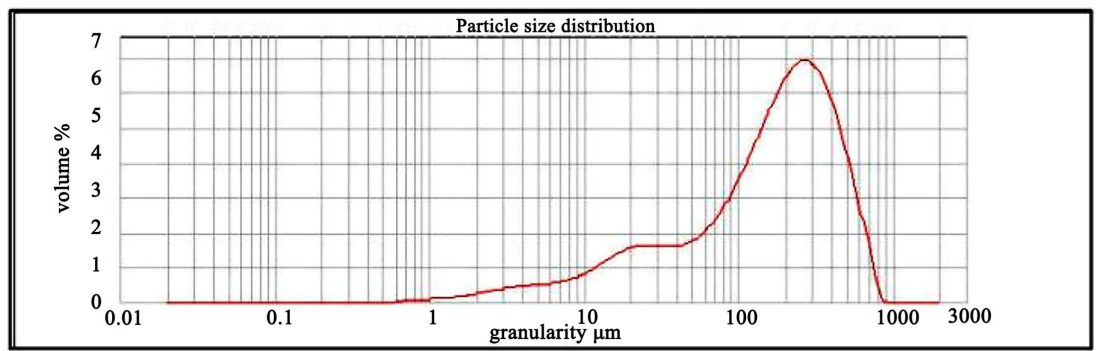

Figure 2. Particle size distribution of anti-collapse and anti-seepage drilling fluid.

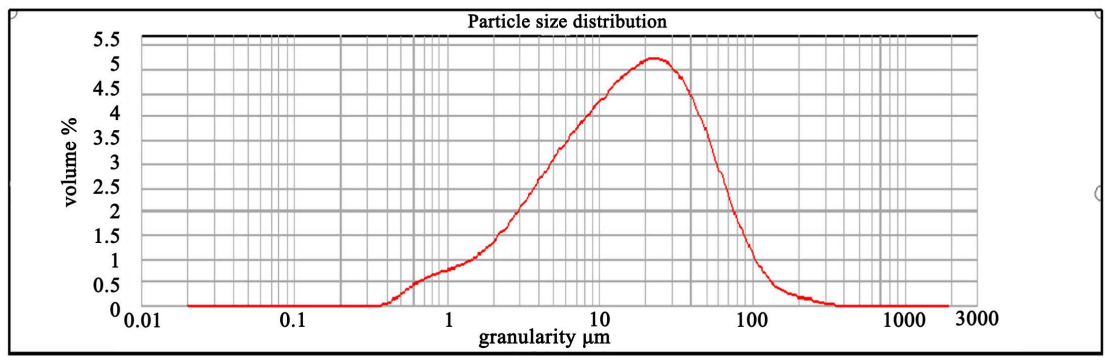

Figure 3. Particle size distribution diagram of conventional drilling fluid. 
of $100 \mathrm{mD}$ and $200 \mathrm{mD}$ is relatively low, indicating that both conventional drilling fluids and anti-collapse and anti-leakage drilling fluids have good plugging ability for low porosity and low permeability shale reservoirs. When the sand tray permeability is $400 \mathrm{mD}$ and $800 \mathrm{mD}$, the filtration loss of the anti-collapse and anti-leakage drilling fluid is obviously smaller than that of the conventional drilling fluid, which indicates that the addition of four functional treatment agents into the conventional drilling fluid plays an obvious plugging effect, improves the film-forming plugging property of the drilling fluid, reduces the pressure transfer of the drilling fluid, and improves the wellbore wall stability.

c) Pressure transmission experiment

The natural core with a length of $50 \mathrm{~mm}$ and a diameter of $25 \mathrm{~mm}$ was fractured into two valves, and the copper wires with diameters of $0.12 \mathrm{~mm}, 0.24 \mathrm{~mm}$ and $0.38 \mathrm{~mm}$ were fixed with 502 glue on the fracture surface of one valve, as shown in Figure 5. $\left(A_{1}\right)\left(A_{2}\right) 0.12$ mm crack; $\left(B_{1}\right)\left(B_{2}\right) 0.24$ mm crack; $\left(C_{1}\right)\left(C_{2}\right)$ $0.38 \mathrm{~mm}$ crack) Then the two valves are closed and placed in the rubber cylinder of the core gripper to form cracks with different sizes, which are used as the filter medium for pressure transfer experiments. The upstream displacement pressure P0 increased by $1 \mathrm{MPa}$ every $30 \mathrm{~min}$, increased to $6 \mathrm{MPa}$ in $180 \mathrm{~min}$, and then stabilized to $6 \mathrm{MPa}$, and the downstream pressure was $0 \mathrm{MPa}$. Schematic diagram of the experimental device is shown in Figure 6. The variation law of the downstream pressure P1 with time T (P0) was measured when the displacement of conventional drilling fluid and anti-collapse drilling fluid passed through the filtering medium. The results are shown in Figure 7.

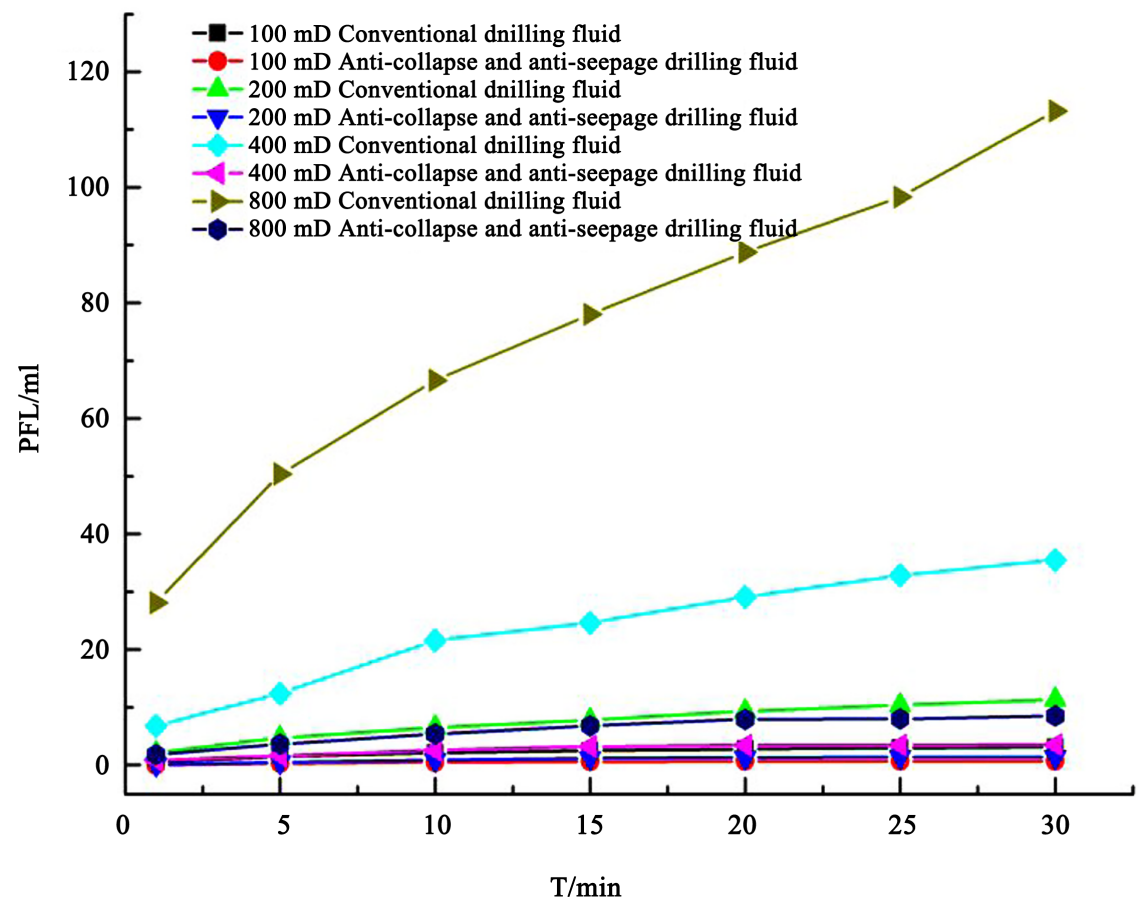

Figure 4. Drilling fluid plugging performance of sand discs with different permeability. 


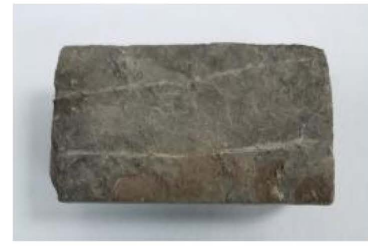

$\left(A_{1}\right)$

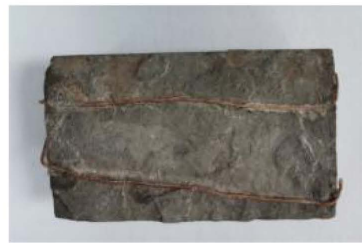

$\left(\mathrm{A}_{2}\right)$

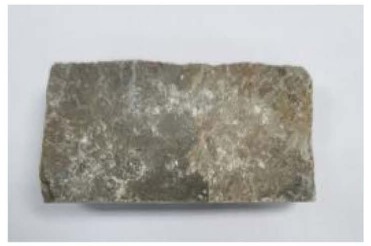

$\left(\mathrm{B}_{1}\right)$

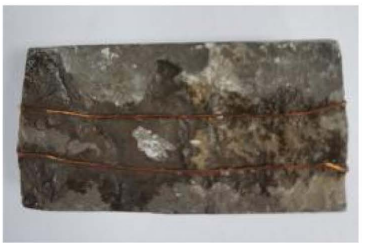

$\left(\mathrm{B}_{2}\right)$

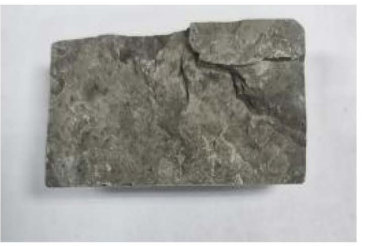

$\left(\mathrm{C}_{1}\right)$

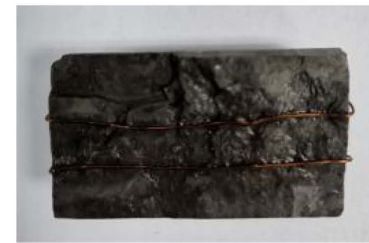

$\left(\mathrm{C}_{2}\right)$

Figure 5. Natural cores with different fracture sizes.

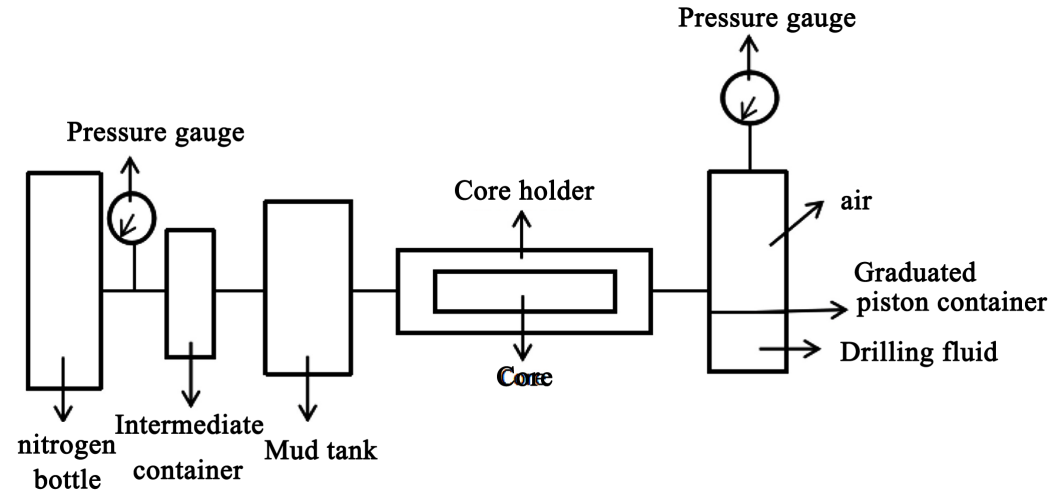

Figure 6. Schematic diagram of displacement pressure experiment device.

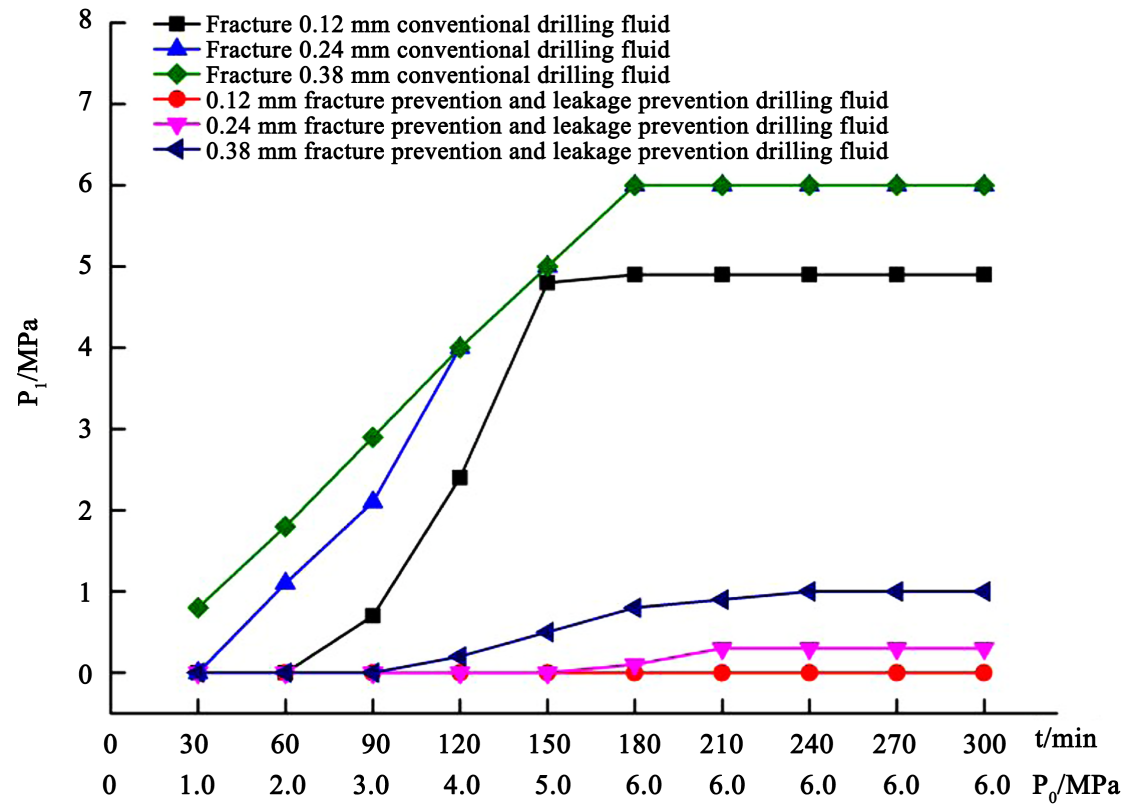

Figure 7. The downstream pressure $\mathrm{P} 1$ changes with time $\mathrm{T}(\mathrm{P} 0)$. 
As shown in Figure 7, for cores with fractures of $0.12 \mathrm{~mm}, 0.24 \mathrm{~mm}$, and 0.38 $\mathrm{mm}$, there was little plugging with conventional drilling fluids. The anti-collapse and anti-leakage drilling fluid can completely seal the $0.12 \mathrm{~mm}$ fracture, and the displacement pressure is increased to $6 \mathrm{MPa}$, while the downstream pressure is still $0 \mathrm{MPa}$. For the core with $0.24 \mathrm{~mm}$ fracture, the downstream pressure is 0.1 $\mathrm{MPa}$ when the displacement pressure increases to $6 \mathrm{MPa}$, indicating that the anti-caving and anti-leakage drilling fluid can still seal the $0.24 \mathrm{~mm}$ fracture. For the core with $0.38 \mathrm{~mm}$ fracture, the upstream displacement pressure is $5 \mathrm{MPa}$, and the downstream pressure is $0.5 \mathrm{MPa}$. With the increase of displacement pressure, the downstream pressure is only $16.7 \%$ of the displacement pressure, and the pressure transfer value is not large. It shows that the anti-sloughing and anti-leakage drilling fluid has a good sealing ability for cores with fracture width below $0.38 \mathrm{~mm}$.

\section{Field Application of Drilling Fluid System}

In August 2019, the system was successfully tested in the Longmaxi Formation in Fuling Reef Block. MEG, LFGB, LCFA, and BXLZ were added gradually, starting at a depth of $3078 \mathrm{~m}$. The performance of drilling fluid in the whole well section is shown in Table 3. As can be seen from Table 3, after the addition of the four treatment agents into the drilling fluid, the filtration loss decreased significantly, the rheological properties of rock carrying and sand returning were normal, and there was no block falling. The tripping, casing running and cementing operations were relatively smooth, showing good plugging, lubricity and the ability to timely seal off and inhibit fracture expansion. Under the condition of ensuring the stability of the wellbore, the triaxial mechanical drilling rate reached $11.23 \mathrm{~m} / \mathrm{h}$, the drilling was completed successfully to $4434 \mathrm{~m}$, and the horizontal section reached $1739 \mathrm{~m}$, setting a record for the horizontal distance of water-based drilling fluid. The experimental results show that the drilling fluid can fully meet the normal drilling needs of shale gas, which provides a choice space and a new idea for the selection of drilling fluid system for shale gas development.

Table 3. Drilling fluid performance data of test wells.

\begin{tabular}{ccccccccc}
\hline $\begin{array}{c}\text { Well } \\
\text { deep/m }\end{array}$ & temperature ${ }^{\circ} \mathrm{C}$ & $\begin{array}{c}\rho \\
\mathrm{g} / \mathrm{cm}^{3}\end{array}$ & $\mathrm{PV} / \mathrm{mPa} \cdot \mathrm{s} / \mathrm{Ya}$ & $\begin{array}{c}\mathrm{GEL} \\
\mathrm{Pa} / \mathrm{Pa}\end{array}$ & $\mathrm{PH}$ & $\mathrm{FL}_{\mathrm{API}} / \mathrm{ml}$ & $\mathrm{FL}_{\mathrm{HTHP}} / \mathrm{ml}^{2}$ \\
\hline 2360 & 51 & 1.38 & 37.0 & 15.0 & $2 / 4$ & 9 & 3.0 & 9.3 \\
2556 & 51 & 1.42 & 40.0 & 18.0 & $3 / 5$ & 10 & 3.1 & 9.6 \\
2818 & 51 & 1.48 & 43.0 & 20.0 & $3 / 7$ & 10 & 3.2 & 9.5 \\
3256 & 51 & 1.53 & 45.0 & 21.0 & $4 / 9$ & 10 & 2.0 & 7.3 \\
3795 & 54 & 1.55 & 50.0 & 21.0 & $6 / 12$ & 10 & 1.6 & 7.2 \\
4012 & 54 & 1.55 & 53.0 & 20.0 & $6 / 12$ & 10 & 1.8 & 7.3 \\
4434 & 54 & 1.55 & 55.0 & 20.0 & $6 / 13$ & 9.5 & 2.0 & 7.4 \\
\hline
\end{tabular}




\section{Conclusions}

Based on the analysis of the physical properties of the shale in the Fuling block, this paper carried out a study on the formulation of the anti-collapse and anti-leakage drilling fluid system, and made relevant evaluations of the rheology, temperature resistance, inhibition and plugging properties of the system. And it was applied on-site in the Fuling Reef Block. Conclusion as below:

1) Four special functional treatment agents MEG, LFGB, LCFA and BXLZ are introduced into conventional water-based drilling fluids, and an anti-collapse and anti-leakage drilling fluid system suitable for the development of hard and brittle shale and shale gas is selected: $2.5 \%$ Sodium Bentonite $+0.15 \% \mathrm{NaOH}+$ $0.15 \% \mathrm{KPAM}+1 \% \mathrm{LV}-\mathrm{PAC}+3 \% \mathrm{KCl}+0.5 \% \mathrm{LCFA}+3 \% \mathrm{XCS}+3 \% \mathrm{SMP}-\mathrm{II}+$ $2 \%$ BXLZ $+5 \%$ MEG $+2 \%$ LFGB $+3 \%$ SPNH $+0.2 \%$ XY- $27+$ barite $(1.6$ $\left.\mathrm{g} / \mathrm{cm}^{3}\right)$.

2) The anti-sloughing and anti-leakage drilling fluid has good rheological properties, low filtration loss and temperature resistance up to $140^{\circ} \mathrm{C}$; can effectively prevent debris hydration, dispersion and expansion. The diameters of the plugging agents in the drilling fluid ranged from 100 to $500 \mu \mathrm{m}$, and the plugging properties of the 400 and $800 \mathrm{MD}$ sand plates and $0.12 \mathrm{~mm}, 0.24 \mathrm{~mm}$ and $0.38 \mathrm{~mm}$ microfractures were very good.

3) The drilling fluid in August 2019 in Fuling rock block successfully trial was carried out, showing good rheology, solid wall blocking resistance, lubricity, and inhibiting sealing cracks and crack propagation control capability is strong, drilling and cementing operation smoothly, to implement environmental protection green Fuling shale gas drilling provides new technical ideas and solutions.

\section{Acknowledgements}

First of all, I would like to express my deepest gratitude to my teacher, Professor Luo Chunzhi, who guided me in the design of the experiment and the writing of the thesis. Without her enlightening guidance and patience, this paper would not have reached its current form. I sincerely thank my classmates Zhang Chujun, Zou Yanlin, Li Xueting, and Zhang Huan in the laboratory for their support and encouragement.

\section{Conflicts of Interest}

The authors declare no conflicts of interest regarding the publication of this paper.

\section{References}

[1] Sun, J.S., Liu, J.P., Yan, L.L., et al. (2016) Current Status of Water-Based Drilling Fluid Technology for Shale Gas Wells at Home and Abroad and Development Direction in China. Drilling Fluids and Completion Fluids, 33, 1-8.

[2] Zhou, L.B. (2017) Research and Application Progress of Strong Inhibitory Water-Based Drilling Fluids at Home and Abroad. Guangdong Chemical Industry, 44, 
127-129.

[3] Jiang, G.C., Dong, T.F., Zhang, X.M., et al. (2018) Research and Application of XZ-New High-Performance Water-Based Drilling Fluid. Drilling Fluids and Completion Fluids, 35, 49-55.

[4] Zhang, P., Xu, H.L., Wang, Z., et al. (2018) Laboratory Evaluation of a High-Performance Shale Gas Water-Based Drilling Fluid System Formulation. Energy and Chemical Industry, 39, 44-48.

[5] Yao, R.G. (2017) Laboratory Research on Non-Toxic and Environmentally Friendly High-Performance Water-Based Drilling Fluids. Drilling Fluids and Completion Fluids, 34, 16-20.

[6] Si, X.Q. and Wang, Z.H. (2019) Research Progress and Development Trend of Green and High-Performance Water-Based Drilling Fluids. Applied Chemical Industry, 48, 1980-1983.

[7] Wang, X., Liu, Y.H., Zhang, M., et al. (2010) Research on Shale Gas Formation Conditions and Influencing Factors of Reservoir Formation. Natural Gas Geoscience, 21, 350-356.

[8] Li, J., Jin, W.J., Wang, L., et al. (2016) Using Nuclear Magnetic Resonance Technology to Determine the Pore Size Distribution of Organic and Inorganic Pores-Taking Silurian Longmaxi Formation Shale Gas Reservoir in Fuling Area of Sichuan Basin as an Example. Petroleum and Natural Gas Geology, 37, 129-134.

[9] Yu, B.S. (2012) The Particularity of Shale Gas Reservoirs and Their Evaluation Ideas and Content. Frontiers of Earth Science, 19, 252-258.

[10] Zhao, D.F., Xie, D.L., Zang, J.C., et al. (2014) Mineral Composition of Shale Reservoir and Related Discussion. Coal Technology, 33, 92-95.

[11] Pan, T., Jiang, G., Sun, W.H., et al. (2016) The Heterogeneity of Longmaxi Formation Shale Reservoir in Weiyuan Area, Sichuan Basin. Fault Block Oil and Gas Field, 23, 423-428.

[12] Wang, Y.M., Wang, H.K., Zhang, C.C., et al. (2017) Evaluation of Fracture Pores in the Deep Wufeng-Longmaxi Formation in the Southern Sichuan Basin. Petroleum Exploration and Development, 44, 531-539. 